\title{
Correction to: Impact of changes in the labor force and innovative agro-based food industry clusters on primary and food-beverage industries, and regional economies in Japan's depopulating society
}

\section{Suminori Tokunaga ${ }^{1}$ (D) $\cdot$ Mitsuru Okiyama $^{2}$}

Published online: 20 October 2021

(C) The Japan Section of the Regional Science Association International 2021

\section{Correction to: Asia-Pacific Journal of Regional Science https://doi.org/10.1007/s41685-021-00210-x}

In the original publication of the article, figure citations were incorrect in the following occurrences inside the text and it is updated in this correction.

1 Under the section 3.2 Structure of the 4SCGE mode.

- Fig. 3 should read as Fig. 5 in the following sentence "... The overview of our 4SCGE model is presented...".

- In same paragraph, Fig. 4 should read as Fig. 6 in the following sentence “... The domestic production block has...".

- Further, under the same section, on next page, Fig. 5 should read as Fig. 7 in the following sentence "Second, for the household block, we formulated ...".

- In addition, Fig. 6 should read as Fig. 8 in the following sentence "... The savings-and-investment block in ...".

- Finally, under the same section, Fig. 7 should read as Fig. 9 in the following sentence "... Fourth, although the trade block includes exports and ...".

2 In footnote 10, Fig. 8 should read as Fig. 3 and Fig. 9 should read as Fig. 4.

The original article can be found online at https://doi.org/10.1007/s41685-021-00210-x.

Suminori Tokunaga

tokunaga@reitaku-u.ac.jp

Mitsuru Okiyama

okiyama.m@gmail.com

1 Faculty of Economics and Business Administration, Reitaku University, 2-1-1, Hikarigaoka, Kashiwa, Chiba 277-8686, Japan

2 Reitaku Institute of Political Economics and Social Studies, Reitaku University, 2-1-1, Hikarigaoka, Kashiwa, Chiba 277-8686, Japan 
3 Under the section 4.2.1.1 Design and result of Simulation 1a,

- Fig. 4 should read as Fig. 6 in the following sentence "... Therefore, the simulation is repeated for changing the efficiency ..." In addition, on the next paragraph, Fig. 8 should read as Fig. 3 in the following sentence "The column graph of Simulation 1a ...".

4 Under the section 4.2.2.1 Designs and results of Simulation 2a,

- Fig. 8 should read as Fig. 3 in the following sentence “... The following results are revealed through the column graph ...".

5 Under the section 4.3.2 Policy simulation results,

- In the first paragraph, Figure 9 and Fig. 9 should read as Figure 4 and Fig. 4, respectively.

- In addition, on the same page, in footnote 27, Fig. 9 should read as Fig. 4.

6 Finally, under the section "Appendix 1: Structure of the four spatial CGE (4SCGE) model", in the second line of the first paragraph, "below (Fig. 5)" should read "(Fig. 5)." In the second line of the second paragraph, Fig. 4 should read Fig. 6. In the 5 th line after eq. (15), Fig. 5 should read Fig.7. In the same paragraph before eq. (16), Fig. 6 should read Fig. 8 and Fig. 7 should read Fig. 9 after eq. (16).

7 In addition, in footnote 8, citation of Fig. 3, 4 were missing. The correct footnote should read as " 8 For more information on the regional SAM, see Tokunaga et al. (2017) and Fig.3, 4.”

The original article was updated.

Publisher's Note Springer Nature remains neutral with regard to jurisdictional claims in published maps and institutional affiliations. 